\title{
Autores brasileiros na página literária do Jornal da Manhã (1885-1892)
}

\author{
Brazilian authors in the literary page of Jornal da Manhã (1885-1892)
}

\author{
ELSA PEREIRA \\ Faculdade de Letras da Universidade do Porto - Porto - Portugal
}

-

\begin{abstract}
Resumo: Considerado um dos melhores diários aparecidos no Porto do último quartel do século XIX, o Jornal da Manhã foi o primeiro diário português a incluir uma página semanal inteiramente dedicada à literatura. Esta secção literária, que se publicou entre 1885 e 1892 , inscreveu nas suas folhas um leque variado de autores brasileiros, testemunhando o interesse dos portuenses por tudo o que ia acontecendo no outro lado do Atlântico, inclusivamente em termos literários. Pela sua relevância nas relações interculturais dos dois países, o artigo apresenta um inventário geral das colaborações brasileiras que se publicaram na página literária do jornal português.
\end{abstract}

Palavras-chave: Escritores; Brasileiros; Portugal; Periódicos; Séc. XIX

\begin{abstract}
Considered one of the best newspapers that appeared in Oporto at the end of the 19th century, Jornal da Manhã was the first Portuguese daily paper to include a weekly page entirely dedicated to literature. This literary section, which was published between 1885 and 1892, included a wide range of Brazilian authors, testifying the interest that people from Oporto took on everything that was happening on the other side of the Atlantic. Given its interest for the intercultural relations between both countries, this article presents a list of the Brazilian collaborations that were published in the literary page of the Portuguese newspaper.
\end{abstract}

Keywords: Brazilian; Writers; Portugal; Periodicals; 19th century

Estudar o século XIX português, em termos de imprensa, é uma tarefa difícil, antes de mais, pela inexistência de uma completa compilação hemerográfica. Se, desde cedo, o incumprimento do depósito legal de publicações impossibilitou as bibliotecas de formarem acervos completos, a ausência de uma política sistemática de microfilmagem, que se estenda para lá das paredes da Biblioteca Nacional ${ }^{1}$, tem deixado muitas raridades bibliográficas à mercê de leitores pouco cautelosos, até a consulta se tornar absolutamente impraticável. Esta contingência, por si só, inviabiliza, à partida, uma análise exaustiva dos periódicos vindos a lume em Portugal, e especificamente no Porto, na segunda metade do século XIX.

Num estudo intitulado "Jornais e revistas do Porto no tempo de Camilo", Francisco Ribeiro da Silva registou, só entre 1850 e 1890, a publicação de pelo menos 68 jornais diários. A estes haveriam ainda de se somar os semanários, "os quinzenários, os tri e os bi-semanários, os mensais, os bimestrais e os trimestrais" (SILVA, 1990, p.50), perfazendo um saldo final deveras surpreendente, mesmo se levarmos em consideração que esses títulos não chegaram, evidentemente, a coexistir todos. $\mathrm{O}$ certo é que, no último quartel do século, o número de jornais publicados na capital do Norte aumentou exponencialmente ${ }^{2}$; facto que não poderá ser explicado apenas pelo aumento demográfico então registado ${ }^{3}$, já que mais de metade da população portuense era analfabeta e, consequentemente, não lia jornais.

\footnotetext{
1 A exceção será talvez a Hemeroteca Municipal de Lisboa, que disponibiliza em linha a consulta de alguns jornais e revistas, sobretudo lisboetas, caídos em domínio público. <http://hemerotecadigital.cm-lisboa.pt/>.

2 Segundo Francisco Ribeiro da Silva (1990, p.50), se em 1850 o total de diários publicados no Porto não ultrapassava a meia dezena, quarenta anos mais tarde, esse número ascenderia a 18. A mesma conclusão poderia, de resto, ser alargada à globalidade dos periódicos aparecidos em todo o país. No "Jornalismo comparativo de Portugal e Hespanha" que a Revista Universal publicou a 14 de outubro de 1841, inventariavam-se 36 periódicos publicados em território português (apud RODRIGUES, 1998, p. 184); quarenta e nove anos mais tarde (janeiro de 1890), o Jornal de Noticias dava conta de 188 jornais, publicados ao longo do ano de 1889 .

3 Informa Fernando Sousa (1988, p. 12) que, de 87.000 habitantes

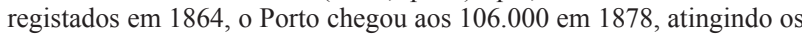
139.000 habitantes em 1890.
} 
A justificação para esta manifesta abundância de publicações periódicas terá de ser procurada, antes de mais, nas movimentações político-ideológicas que dominavam o meio e que aparecem plasmadas nos próprios títulos e subtítulos ostentados por muitas dessas publicações: $O$ Porto Liberal, Diário Progressista, A República, etc. Ao inscrever-se explicitamente numa determinada linha de ação política, cada jornal assegurava assim, à partida, a assinatura dos seus correligionários, bem como uma série de apoios publicitários, cujo cancelamento, na sequência de dissidências partidárias, acabava inevitavelmente por determinar o fim da respetiva publicação. Tratavase portanto de uma indústria jornalística instável, cuja viabilidade financeira dependia largamente das receitas provenientes da publicidade ${ }^{4}$, e cuja dinâmica se poderá relacionar também com o próprio meio editorial brasileiro.

$\mathrm{Na}$ verdade, além do valor das assinaturas (algumas das quais seguiam com os emigrantes, nos paquetes que regularmente cruzavam o Atlântico ${ }^{5}$ ), uma parte significativa das receitas obtidas pelos jornais do Porto provinha da divulgação de novidades editoriais, nestas incluindo-se também as do Brasil. A Carne, de Júlio Ribeiro, e Poesias, de Olavo Bilac, são dois exemplos de publicações brasileiras que, ao serem impressas na Empresa Literária e Tipográfica do Porto, pela mão do editor António Maria Teixeira, de São Paulo ${ }^{6}$, mereceram ampla divulgação nos jornais portuenses da altura, indiciando, desde logo, o protagonismo assumido pela imprensa periódica no mercado editorial.

Por outro lado, e numa altura em que literatura e jornalismo se fundiam quase sempre na figura polígrafa do escritor-jornalista ${ }^{7}$, a presença literária nos periódicos nortenhos ia muito além do comum folhetim, publicado em pé de página. E a esta observação não seria talvez alheia a circunstância de pelos periódicos da Invicta terem passado, no último quartel do século XIX, praticamente todos os escritores naturais da cidade ou aí radicados, caso de Alexandre Braga, Basílio Teles, Bento Carqueja, Emídio de Oliveira, Joaquim de Vasconcelos, Luís de Magalhães, Oliveira Martins, Queirós Veloso, Sampaio Bruno, entre outros.

Será pois neste contexto de efervescência literária que o Jornal da Manhã (1872-1892), um dos melhores diários aparecidos no Porto do último quartel do século XIX e o segundo de maior circulação ${ }^{8}$, se afirmará como o primeiro diário português a publicar semanalmente uma página frontal inteiramente dedicada à literatura.

Esta seção literária, que ocupava a totalidade da página inicial, surgiu com a primeira edição regular do Jornal da Manhã às segundas-feiras, a 6 de abril de $1885^{9}$, dando então origem a um assinalável incremento das tiragens que, nesse dia da semana, aumentavam em cerca de $30 \%{ }^{10}$. De então em diante, a página literária deste diário seria publicada assíduamente às segundasfeiras, até ao final de 1890, altura em que transita para o domingo ${ }^{11}$, entrando então em declínio, com a cedência progressiva de espaço aos acontecimentos que faziam a atualidade política, até à extinção do jornal, em 1892.

Durante os sete anos que durou a sua publicação, a página literária do Jornal da Manhã sobressaiu, todavia, pelo interesse e variedade das colaborações, inscrevendo nas suas páginas alguns nomes sonantes da literatura nacional, bem como um leque variado de autores brasileiros, agrupados, a partir de 1889 , numa seção intitulada "Parnaso Brasileiro".

A adoção de um título desta natureza deixa, no entanto, entrever uma série de fragilidades imediatas, que uma catalogação do tipo literatura portuguesa $v s$. literatura brasileira coloca, à partida. Se o caso de um Filinto de Almeida, um Narciso de Lacerda, um Francisco Gomes de Amorim ou um Gaspar da Silva (escritores nascidos no Porto / Póvoa de Varzim / Braga, mas que emigraram para o Brasil - acabando o primeiro por se naturalizar) são já suficientemente problemáticos, não sem razão, desabafava Camilo, a propósito de Gonçalves Crespo:

4 A representação da publicidade nos periódicos portuenses pode ser comprovada pela verba do selo do anúncio escriturada no distrito do Porto. Segundo a Conta Geral da Administração Financeira do Estado na Metrópole, esse valor atingiu os $849 \$ 716$ reis, no ano económico de 1889-90 (TENGARRINHA, 1965, p. 204).

5 Segundo J. F. Alves, entre 1836 e 1879, o Brasil correspondia a 90-99\% dos destinos da emigração portuense (ALVES, 1994, p. 177). A partir dos registos de passaportes existentes no Governo Civil do Porto, o autor chega ao impressionante número de 120.000 pessoas que, durante esse período, embarcaram rumo a terras de Vera Cruz (ALVES, 1994, p. 244).

6 A. M. Teixeira era proprietário da Livraria Teixeira, em São Paulo. Depois do seu regresso a Portugal, iria fundar a Livraria Clássica, editando Olavo Bilac (Crítica e Fantasia) e Sílvio Romero (A Pátria Portuguesa), entre outros brasileiros.

7 De uma forma geral, todos os grandes escritores do século XIX participaram ativamente nos jornais da época. Aproveitando a expressão de François Mauriac, Jean Touzot sublinha precisamente o hibridismo que caracteriza o écrivan journaliste: "Pour mériter d'être rattaché à cette espèce bizarre, il ne suffit pas de donner de temps à autre un article à un journal ou d'accorder un entretien entre deux romans. Il faut se sentir une responsabilité devant l'opinion, comme vertu d'un contrat qui impliquerait régularité et durée" (TOUZOT, 1998 , p. 10).

8 Isso mesmo se depreende da seguinte nota, publicada na primeira página da edição de 16/08/1886: "O Jornal da Manhã, em virtude da tiragem que fez, em virtude da sua publicação todos os dias, inclusivamente às segundas-feiras, e em virtude do grande número de agencias e vendedores que tem, tanto n'esta cidade como no paiz, mormente desde Coimbra até ao extremo norte do reino, é o segundo periódico portuense de mais circulação".

9 De 1872, ano da sua fundação, até 1885 , este diário publicava-se todos os dias da semana, exceto à segunda-feira. A partir do momento em que se começou a publicar também à segunda, esse número passa a estar quase inteiramente consagrado à literatura, já que o diário era composto por duas folhas, a última das quais estava reservada aos anúncios publicitários.

10 Enquanto a tiragem diária se situava entre os 5500 (em 1886) e os 10 000 (em 1888) exemplares, às segundas-feiras esse número ascendia aos 7600 (em 1886) - 14000 (em 1888) exemplares.

11 Anote-se, entretanto, que só muito mais tarde (em 1907) será consagrado, pela primeira vez em Portugal, o princípio geral da obrigatoriedade do descanso semanal, coincidindo preferencialmente com o domingo. 
Chamam-lhe uns ateniense, outros brazileiro: eu quero que elle seja portuguez, porque levo o amor da minha patria ao latrocinio d'um poeta que me diz pouco do sabiá no raminho da jatubá, e da araponga na copa do jaquitibá [...]. É portuguez como Garrett, francez como Gautier, americano sentimental como Longfellow, humorist como Godfrey Saxe, e hespanhol como Campoamor. É de todos os paizes que têm poetas com intercadencias de tristezas, risos, energias satanicas e angelicaes maviosidades; mas, na linguagem, é portuguez sem joio (BRANCO, 1927, I, p. 101).

Talvez por isso, a página literária do Jornal da Manhã tenha prescindido, nos seus primeiros anos, de um rótulo desta natureza, preferindo antes incluir discretas notas parentéticas, relativamente à proveniência geográfica de alguns dos nomes contemplados, que, embora desnecessárias para os autores consagrados, se impunham no caso, por exemplo, de um certo Merciano, expressamente identificado como "brasileiro" (Jornal da Manhã, 29/08/1887, p. 1).

Problemático ou não, o certo é que o Parnaso aludido se tornou bem mais eclético, ao transferir-se para terras brasileiras, passando a incluir não apenas poesia, mas também ficção e crónica, embora com um claro predomínio da primeira. Aproveitando a imagem clássica, quase apeteceria dizer que, transplantado dos confins da Beócia para a Lagoa de Guanabara, o Parnaso do Jornal da Manhã se metamorfoseou num Corcovado de formas generosas... ou não fossem estas colaborações brasileiras maioritariamente assinadas por escritores naturais do Rio de Janeiro - caso de Olavo Bilac, Valentim de Magalhães, Luís Murat, Mário Pederneiras, Osório Duque-Estrada ou Mário de Alencar, etc..

A tal circunstância não seria porventura alheio o facto de esta cidade absorver a esmagadora maioria dos emigrantes portuenses ${ }^{12}$. Numa altura em que as empresas jornalísticas não dispunham dos revolucionários meios de comunicação à distância, a negociação do jornal com os colaboradores da antiga colónia teria de se fazer unicamente através dos vapores que cruzavam o Atlântico, pelo que, aportando ao cais do Rio de Janeiro praticamente todos os navios vindos de Portugal, a acessibilidade dos contactos era significativamente maior no caso dos escritores fixados na capital brasileira. E durando essas viagens pouco menos de um mês, é de supor que as colaborações fossem acordadas com alguma antecedência, mediante envio de composições em série, que a redação do jornal depois geria, de acordo com as suas necessidades e com o planeamento das suas páginas literárias.

A verdade porém é que, na impossibilidade de apurarmos mais pormenores acerca dos moldes em que essas colaborações se efetuavam, ficaremos sem saber até que ponto a disponibilização dos textos seria efetivamente acordada, ou se, pelo contrário, resultaria de uma apropriação ilícita, a partir de livros ou jornais que ao Porto chegavam, no regresso dos vapores. A favor da primeira hipótese, parece abonar a indicação de "inédito" que acompanha certas composições - caso de Fagundes Varela (Jornal da Manhã, 22/09/1890) - ou ainda o facto de alguns textos aparecerem datados apenas um mês antes da sua inclusão no jornal portuense - por exemplo, Álvaro Lagrim (Jornal da Manhã, 16/08/1886) ou Duarte de Azevedo (Jornal da Manhã, 25/02/1889). No entanto, o segundo cenário afigura-se igualmente verosímil, sobretudo se pensarmos que as leis internacionais de direito autoral eram ainda pouco respeitadas ${ }^{13}$, e que a transcrição de textos era uma prática corrente na imprensa da altura como aliás explicitamente se indica, num texto transcrito d'O Mercantil do Rio (Jornal da Manhã, 13/10/1890).

Em todo o caso, o que parece incontestável é o efetivo interesse dos portuenses por tudo o que ia acontecendo no outro lado do Atlântico ${ }^{14}$, inclusivamente em termos literários. A popularidade dos autores brasileiros corroborada por elogiosos comentários de Teófilo Braga, no seu Parnazo Portuguez Moderno (BRAGA, 1877) - acabaria aliás por dar origem no Porto a uma série de edições ilegais, de que foram vítimas poetas como Casimiro de Abreu ${ }^{15}$ ou Fagundes Varela, segundo testemunha o próprio Camilo:

Os apreciadores da lyra brazileira distinguem com especial louvor Fagundes [Varela]. É bastante citado este paulista, e tão lido cá, ao que parece, que a especulação a reimprimiu no Porto em 1875, reproduzindo-lhe o prefacio de 1861 (BRANCO, 1927, II, p. 203).

\footnotetext{
${ }^{12} \mathrm{O}$ Rio absorvia a grande maioria dos emigrantes portuenses, anos havendo em que essa percentagem chegou a ultrapassar os $80 \%$. "Nos finais do século, a concorrência ao Rio de Janeiro (55\%) surge ainda do Pará, com força renovada (17\%) e de S. Paulo (10\%)" (ALVES, 1994 p. 242).

${ }^{13}$ Embora o primeiro tratado multilateral de tendência universalista tenha sido instituído com a Convenção de Berna de 1886 , nem todos os sistemas legislativos nacionais eram compatíveis entre si. Só em 1954, com a Convenção de Genebra, essas falhas seriam colmatadas.

${ }^{14}$ Uma passagem pelas páginas dos muitos periódicos da altura deparanos com um caudal intenso de notícias provenientes do Brasil, desde novidades relativas ao mercado monetário e à cotação de produtos no mercado brasileiro, até ao anúncio de portugueses por lá falecidos e respetivas disposições testamentárias, bem como outros tantos que regressavam da ex-colónia, passando pelo anúncio de partidas dos navios e todo o mais noticiário referente à ação governamental, aos efeitos das epidemias, às representações teatrais, etc. Embora alguns jornais mantivessem correspondentes no Rio de Janeiro, a maioria (e nomeadamente o Jornal da Manhã) apoiava os seus noticiários nos jornais brasileiros, chegando mesmo a cobrir várias regiões do país. A este respeito, veja-se, por exemplo, a edição do Jornal da Manhã de 06/10/1891, onde o noticiário extraído dos jornais brasileiros alcança notícias de Santos, Bahia, Pará, Rio Grande do Sul e Pernambuco, além, evidentemente, do Rio de Janeiro.

${ }^{15}$ A este propósito, veja-se o nosso artigo (PEREIRA, 2014).
} 
E mesmo quando a lira brasileira enfrentava o demolidor sarcasmo do escritor português, o certo é que o seu Cancioneiro Alegre de Poetas Portuguezes e Brazileiros terá, no mínimo, contribuído para aumentar a curiosidade em relação a alguns desses autores. A isto haveria ainda de somar-se o contributo de publicações como o Almanaque de Lembranças Luso-brasileiro ou mesmo o próprio Jornal da Manhã que, ao incluir nas suas páginas perfis biográfico-críticos de escritores como José de Alencar (Jornal da Manhã, 7/4/1890), Raimundo Correia (Jornal da Manhã, 20/6/1887), Joaquim Nabuco (Jornal da Manhã, 17/10/1887) ou Augusto Emílio Zaluar (Jornal da Manhã, 8/3/1886 e 22/4/1889), acabou por se afirmar também como um agente importante na divulgação da literatura brasileira, abrindo portas a uma prática continuada por outros periódicos portuenses.

Entre esses sobressai naturalmente o Jornal de Notícias (lançado a 3 de junho de 1888), na medida em que também este incluiu, logo a partir do seu no $\mathbf{0}$, uma primeira página dedicada à literatura, exatamente às segundas-feiras e nos mesmos moldes em que vinha acontecendo no Jornal da Manhã - atitude deveras suspeita, especialmente se pensarmos que a fundação do novo jornal surge na sequência de dissidências geradas no seio do Partido Regenerador, logo após a morte de Fontes Pereira de Melo. O prestígio das personalidades que encabeçavam a nova empresa jornalística, aliado ao clima de discórdia que essas mesmas desavenças políticas haviam aberto na redação do Jornal da Manhã, acabaria assim por aliciar para o novo projeto algumas das figuras mais influentes deste diário. E com eles terão seguido talvez alguns dos contactos estabelecidos com os escritores brasileiros que asseguravam colaborações no Jornal da Manhã, como parece sugerir um breve cotejo entre estes e os autores que aparecem publicados na página literária do Jornal de Notícias, entre 1888 e $1891^{16}$.

Perante a fundação do novo diário de tendência regeneradora, o Jornal da Manhã viu assim o seu lugar ser perigosamente ocupado, passando então por um período difícil, que o iria precipitar, em setembro de 1888 , numa desastrosa viragem progressista, até ao seu desaparecimento, em março de 1892:

o jornal entrava devolvido aos montões de exemplares, pela porta da administração, onde o pobre administrador, o velho A. A. Correia [...] amarrava as mãos na cabeça sem saber que fazer á sua vida! Os magnates progressistas, apezar de toda a propaganda feita, não compensavam com as suas assignaturas o numero das que se haviam retirado com a reviravolta do periodico, que desde então foi arrastando uma existência atribulada (BESSA, 1927, p. 242-243).
Deste modo se virava a página de um dos mais importantes jornais que se publicaram no Porto do último quartel do século XIX e, com ela, a presença de autores brasileiros nos suplementos literários de primeira página dos jornais portuenses ${ }^{17}$.

Pela importância deste intercâmbio na história das relações entre os dois países, impõe-se terminar o artigo com o inventário geral das colaborações brasileiras que se publicaram na página literária do Jornal da manhã.

O índice que se segue tem por base as edições do Jornal da manhã publicadas entre 6 de abril de 1885 e 13 de março de 1892. Foram considerados apenas os exemplares disponíveis na Biblioteca Pública Municipal do Porto, faltando portanto os nos 288, 295 e 337 de 1886 , o n⿳⺈ 168 de 1888 , o no 54 de 1890 e os nos $5,46,123,211$ e 217 de 1891. Foram considerados apenas os escritores brasileiros (excluindo os portugueses emigrados). Para facilitar a consulta, dispõem-se as colaborações em duas secções autónomas: textos escritos em verso e em prosa. Em cada uma delas, os autores aparecem dispostos por ordem alfabética, acompanhando os títulos (ou o primeiro verso) que encabeçam as composições e as respetivas datas de publicação.

\section{Textos escritos em verso}

- Achylles Porto Alegre:

No Calvario, domingo 13/12/1891.

- Adolfo de Araújo:

Reconciliação, segunda-feira 6/10/1890;

A Luva, segunda-feira 10/11/1890.

- Adrião Caminha:

A Casinha do Amor (poema datado de Corte, 1886), segundafeira 04/02/1889.

- Affonso Guimarães:

Poetisa (a Cesar Franco), segunda-feira 8/12/1890, domingo 04/01/1891;

Scherzando, domingo 04/01/1891;

Numeros Lyricos, domingo 05/07/1891.

\section{- A. Franco C. Meirelles:}

A captiva (canção de Spronceda), segunda-feira 30/12/1889; Cantico Sagrado (Th. Moore) (poema datado de Bahia, 1880), segunda-feira 06/01/1890.

\footnotetext{
${ }^{16}$ Entre os nomes que figuraram na página literária do Jornal de Notícias, contam-se efetivamente alguns nomes comuns ao Jornal da Manhã: Alberto de Oliveira, Luís Guimarães, Luís Murat, Olavo Bilac, Raimundo Correia, Teófilo Dias, Wenceslau de Queirós, entre outros.

${ }^{17}$ No caso do Jornal de Notícias, a página literária havia já sumido, em finais de 1891, logo após a morte do seu mentor, José Guilherme Pacheco. As preocupações literárias desse jornal irão então reduzir-se ao comum folhetim, publicado em pé de página, e às Crónicas portuenses, assinadas por Barnabá (pseudónimo de Emídio de Oliveira), aos domingos e quintas-feiras.
} 
- Alberto de Oliveira:

Cofre Negro, segunda-feira 29/04/1889;

Rêde selvagem (a Narcisa Amália), segunda-feira 22/07/1889; A camisa de Olga (a Osorio Duque-Estrada), segunda-feira 06/01/1890;

Aldeãs, domingo 26/07/1891;

Nocturno, domingo 24/01/1892.

- Alfredo de Magalhães:

A Nuvem, segunda-feira 28/07/1890;

Esplendida (Das Ardentias), segunda-feira 04/08/1890.

Amore (das Ardentias), segunda-feira 11/08/1890;

Amor de soldado: Blasco (das Ardentias), segunda-feira 11/08/1890;

Olhares (das Ardentias), segunda-feira 08/09/1890;

Manhã de Outono, segunda-feira 08/09/1890.

- Alfredo Peixoto:

Ballada no Mar (ao maestro Henrique Braga), segunda-feira 28/07/1890.

- Alfredo de Sousa:

Virtudes Teologais (versão), segunda-feira 03/03/1890.

- Álvares de Azevedo:

Palida á luz da lampada sombria, segunda-feira 16/08/1886, domingo 31/05/1891.

- Álvares de Azevedo Sobrinho: A tarde, domingo 25/01/1891.

- Álvaro Lagrim: Improviso (poema datado de 29/07/86), segunda-feira 16/08/1886.

- Amelia de Oliveira:

Noite (soneto datado de julho de 1887), segunda-feira 03/10/1887.

Aquele dia (soneto datado de agosto de 1887), segunda-feira 17/10/1887.

- Artur Azevedo:

Queixume, segunda-feira 18/11/1889;

Peccavi, segunda-feira 21/04/1890;

Recordação, segunda-feira 14/01/1889.

- Augusto Cavalcante:

Tarde de Inverno, domingo 20/09/1891.

- Augusto de Lima:

De tarde (poema datado de Leopoldina, 1887), segunda-feira 16/05/1887;

Elevação, segunda-feira 20/06/1887, segunda-feira 23/01/ 1888;

O Polvo (poema datado de Leopoldina, 1887), segunda-feira 27/06/1887;

Flor Carnivora, segunda-feira 05/09/1887;

A herança de Prometeu, segunda-feira 26/09/1887;

Pensamentos fugitivos, segunda-feira 07/11/1887;

Almas Paralelas, segunda-feira 21/11/1887;

Teu nome, segunda-feira 12/12/1887;

Vogando (a Afonso Celso Júnior), segunda-feira 16/01/ 1888;

Correspondencia, segunda-feira 21/07/1890.
- Baronesa de Mamancurá:

Finge, segunda-feira 10/06/1889.

- Baronesa de Mamanguape:

A Perola, segunda-feira 16/09/1889;

Ninho Vazio, segunda-feira 31/03/1890;

Enferma, segunda-feira 28/04/1890.

- Candida Rolim:

Chromos (na forja), segunda-feira 27/02/1888.

- Canto e Melo:

Perdida (poema datado de 30/10/90), segunda-feira 08/12/1890.

- Castro Alves:

Hamilton d'Araujo: Murcham no cálice os jasmins e as rozas, segunda-feira 12/08/1889;

A Canoa Phantastica, segunda-feira 12/11/1888;

Consoladora (a Mademoiselle Maria L.), segunda-feira 17/03/1890;

Trovas (a Guerra Junqueiro), domingo 25/01/1891;

Inverno, domingo 08/02/1891;

Á Entrada da Primavera, domingo 22/03/1891;

Bandolinatas (a Julio Brandão), domingo 19/04/1891;

Sobre a Cova de Hamilton d'Araujo, domingo 09/08/1891.

- Castro Fonseca:

Marinha, segunda-feira 05/04/1886;

Em uma noite de Verão, segunda-feira 17/05/1886;

O ramo verde (poema datado de janeiro de 1886), segundafeira 11/02/1889.

- Cruz e Sousa:

Apòs o Noivado, segunda-feira 01/08/1887;

Glorias Antigas, segunda-feira 12/05/1890;

Luar, segunda-feira 25/08/1890;

Celeste, segunda-feira 15/09/1890;

Canção de Abril, segunda-feira 06/10/1890.

- Damasceno Vieira:

Brasiliana, segunda-feira 22/08/1887;

O nadador, segunda-feira 22/08/1887.

- Demosthenes de Olinda:

Pagina Intima, domingo 02/08/1891.

- Duarte de Azevedo:

Lasciate ogni speranza, voi che'ntrate: Por mim se vae a lobrega morada (soneto datado de S. Paulo, 23 janeiro 1889), segunda-feira 25/02/1889.

- Eloi, o Heroi:

Velhos Typos (poema datado do Maranhão, 1871), segundafeira 25/07/1887.

- Fagundes Varella:

Ballada (inédita), segunda-feira 22/09/1890.

- Filinto de Almeida:

De Madrugada, domingo 17/05/1891;

Madrigal, domingo, 19/07/1891;

No campo (A Machado de Assis), domingo 21/07/1891;

No lar (A A. Cardoso de Menezes), domingo 21/07/1891;

Fallando à alma, domingo 14/02/1892;

Novo sol, domingo 13/03/1892. 
- Flávio Sol:

Convite (poema datado do Brasil), segunda-feira 03/11/1890.

\section{- Francisco Octaviano:}

Morrer, dormir, não mais, termina a vida, terça-feira 25/06/1889.

\section{- Gonçalves Crespo:}

O Velhinho, segunda-feira 12/07/1886;

Um numero do intermezzo, segunda-feira 19/12/1887;

Barcarola (de Th. Gauthier), segunda-feira 12/03/1888, segunda-feira 26/05/1890;

N'um leque, segunda-feira 26/11/1888;

A Bordo (ao meu amigo e mestre J. Penha), segunda-feira 18/03/1889;

Adeus, domingo 09/08/1891;

Mimosa, segunda-feira 18/08/1890;

Odor di femina, domingo 20/12/1891.

- Gonçalves Dias:

Não me deixes, domingo 26/07/1891.

- Guimarães Passos:

Na Orgia, segunda-feira 16/05/1887;

Eterna Historia (poema datado do Rio, 4/87), segunda-feira 06/06/1887;

A Mergulhadora (inspirado em Schiller), segunda-feira 19/11/1888;

Mensageiras, segunda-feira 24/11/1890;

Mudo te vejo agora, o passarinho, domingo 04/01/1892.

- Guilherme de Miranda:

Chorando: n'um album, domingo 20/12/1891;

- Joaquim Nabuco:

Morna (Ossian), domingo 13/12/1891.

- José Bonifácio:

A Lagrima, segunda-feira 05/04/1886; domingo 20/12/1891;

Lendo Anacreonte, segunda-feira 29/11/1886;

Meu Testamento, segunda-feira 13/12/1886;

Aspiração, segunda-feira 24/10/1887;

Camões (poema datado de 1880), segunda-feira 28/01/ 1889 ;

Quê, segunda-feira 01/04/1889;

Deserta a casa está, entrei chorando, segunda-feira 24/11/ 1890;

N'um álbum, domingo 18/01/1891.

- José de Alencar:

Estrela da Tarde, segunda-feira 01/04/1889;

Zelos, segunda-feira 01/04/1889;

Primeira Saudade (A. Lamartine), segunda-feira 23/09/1889.

- José Severiano de Resende:

Sombras que passam, segunda-feira 27/10/1890.

- Julio Cesar da Silva:

A Rosa e o Tumulo (de Victor Hugo), domingo 09/08/1891, domingo 18/10/1891.

- Julio Salusse:

Virgem Morta (poema datado de S. Paulo, 1887), segundafeira 15/08/1887;
Não voltes, segunda-feira 05/05/1890;

Dentro d'alma, segunda-feira 20/10/1890.

- Luiz de Carvalho:

Historia vulgar (conjunto de 2 sonetos datados de S. Paulo, agosto 89 ), segunda-feira 14/10/1889.

\section{- Luiz Delfino:}

A Gloria (das algas e musgos), segunda-feira 28/04/1890;

Libido, segunda-feira 05/05/1890;

Intimas, segunda-feira 23/06/1890;

A Aguia, segunda-feira 30/06/1890;

Levantinas, segunda-feira 11/08/1890;

Luctas, domingo 02/08/1891.

\section{- Luiz Guimarães:}

Arte Poética, segunda-feira 24/10/1887;

Oh Caridade humana! Ingenua Estrella!, segunda-feira 20/08/1888;

A voz das arvores, segunda-feira 12/11/1888;

Temperamentos, segunda-feira 18/02/1889;

Lutuosa, domingo 11/01/1891;

Lá, domingo 30/08/1891;

Eva, domingo 04/01/1892.

\section{- Luiz Guimarães Junior:}

Madrugada na roça, segunda-feira 25/03/1889;

A carta, segunda-feira 23/09/1889.

\section{- Luiz Murat:}

As crianças, segunda-feira 16/05/1887;

Fallando à infancia, segunda-feira 19/09/1887;

Responso final, segunda-feira 17/10/1887;

As núpcias de Amphitrite (a Affonso Celso Júnior), segundafeira 12/03/1888;

N'um álbum, segunda-feira 22/04/1889;

Cordelia (à minha filha), segunda-feira 10/06/1889;

Hymno da Abolição, terça-feira 25/06/1889;

A Minha Mãe: no dia dos seus anos (poema datado de 20 de setembro de 89), segunda-feira 23/06/1890.

- Magalhães de Azeredo:

A Perola, domingo 18/01/1891;

Lucta Estéril, domingo 15/02/1891;

Boneca, domingo 26/04/1891.

\section{- Maria Prot:}

Amor de mãe (poema datado de S. Paulo 1890), domingo 04/01/1890.

- Maria Zalina Rolim:

Mãe (ao Dr. Ezequiel Freire), segunda-feira 11/06/1888;

Adormecida (ao Dr. João Kopke) (poema datado de S. Roque 1888), segunda-feira 21/01/1889;

Pomba ferida, segunda-feira 03/02/1890.

- Marinho de Andrade:

Venenosa, segunda-feira 02/09/1889.

- Mário de Alencar:

Flores e Lágrimas, segunda-feira 24/03/1890.

- Mário Pederneiras:

Intimo, segunda-feira 10/06/1889. 
- Medeiros e Albuquerque:

Vorrei morire, segunda-feira 14/07/1890;

Atheu e Crente, domingo 20/12/1891.

\section{- Merciano:}

Os teus olhos e as Estrellas (poema datado do Rio de Janeiro), segunda-feira 29/08/1887.

- Múcio Teixeira:

Á minha filhinha, segunda-feira 19/03/1888.

- Narcisa Amália:

Crepusculo de Abril (a Zelia Dufour), (poema datado de 14 de abril de 1887), segunda-feira 16/05/1887;

A Nuvem (Theophilo Gauthier), segunda-feira 23/05/1887;

Pelas sombras, segunda-feira 07/01/1889.

\section{- Olavo Bilac:}

A um velho, segunda-feira 20/09/1886;

De volta do baile, segunda-feira 06/06/1887;

Profissão de fé (poema datado do Rio de Janeiro, julho de 1886), segunda-feira 17/12/1888, segunda-feira 04/11/1889;

Bella e traidora! Beijas e assassinas, segunda-feira 07/01/ 1889;

Pantum, segunda-feira 4/3/1889, segunda-feira 24/03/1890;

Á ultima, segunda-feira 11/03/1889;

Rio Abaixo, segunda-feira 18/03/1889;

Barulho Odorante, segunda-feira 01/04/1889;

Ida, segunda-feira 16/09/1889;

Via-lactea (A minha mãe): Sei que um dia não há (e isso é bastante), segunda-feira 11/11/1889, segunda-feira 02/12/ 1889, domingo 11/10/1891;

Via-lactea: Como a floresta secular, sombria, segunda-feira 11/11/1889;

Via-lactea: Dizem todos: '-Outr'ora como as aves', segundafeira 11/11/1889;

Via-lactea: Talvez sonhasse, quando a vi. Mas via, segundafeira 11/11/1889;

Via-lactea: Tantos esparsos vi profundamente, segunda-feira 11/11/1889;

Via-lactea: Tudo olvirás, pois que, bondosa e pura, segundafeira 11/11/1889;

Via-lactea: Á ultima, segunda-feira 18/11/1889;

Via-lactea: De outras que se mostram menos frias, segundafeira 18/11/1889;

Via-lactea: Em que céos mais azues, mais puros ares, segunda-feira 18/11/1889, domingo 21/02/1892;

Via-lactea: Ora (direis) ouvir estrelas! Certo, segunda-feira 18/11/1889;

Via-lactea: Sonhei que me esperavas. E, sonhando, segundafeira 18/11/1889;

Quarenta annos, segunda-feira 02/12/1889;

Solitudo, segunda-feira 02/12/1889;

$\mathrm{Na}$ Thebaida, segunda-feira 09/12/1889;

Sahara Vitae, segunda-feira 25/11/1889, segunda-feira 21/07/1890;

Via-lactea: Como a floresta secular, sombria, domingo 26/07/1891;

Via-lactea (a uma creança): Hontem - néscio que fui! maliciosa, domingo 23/08/1891;
Na estrada da vida, domingo 04/01/1892;

Via-lactea: Em que céos mais azues, mais puros ares, domingo 21/02/1892;

Via-lactea: Deixa que o olhar do mundo emfim devasse, domingo 06/03/1892;

Via-lactea: Em mim tambem, que descuidado vistes, domingo 06/03/1892.

\section{- Osório Duque-Estrada:}

Croquis (a Alberto de Oliveira), segunda-feira 20/01/ 1890;

Conversas de amor, segunda-feira 31/03/1890;

Symphonia matinal, segunda-feira 28/04/1890;

Ara partida (ultimos versos), segunda-feira 25/08/1890;

Flor do Inverno, segunda-feira 26/08/1889;

Rosita, segunda-feira 20/10/1890;

Contricção, segunda-feira 10/11/1890.

- Paulino de Brito:

A um aniversário, segunda-feira 07/07/1890.

- Pedro Luiz:

Amor de mãe, segunda-feira 20/01/1890.

- Pedro Tavares:

Matinal: a Barata Ribeiro (poema datado de S. Paulo, 1890), segunda-feira 27/10/1890.

\section{- Raymundo Correia:}

Perfis românticos: Graziella, segunda-feira 22/02/1886, segunda-feira 18/07/1887;

Perfis românticos: Nathercia, segunda-feira 22/02/1886;

Perfis românticos: Ofelia, segunda-feira 22/2/1886, segundafeira 18/07/1887;

Coerule! Oculi (Th. Gautier), segunda-feira 10/05/1886;

Dezembro (F. Coppée), segunda-feira_/05/1886.

Aria Nocturna, Segunda-feira 31/5/1886, segunda-feira 04/07/1887;

Espelho de Anacreonte, segunda-feira 2/5/1887;

A filha do coveiro, (poema datado de novembro 1884) segunda-feira 06/06/1887;

Hero, segunda-feira 27/06/1887;

Os argonautas (poema datado de novembro 1886), segundafeira 11/07/1887;

Fim de Comedia, segunda-feira 19/09/1887;

O Monge, segunda-feira 26/09/1887;

A Terra e a Nuvem, segunda-feira $06 / 08 / 1888$;

O Anoitecer, segunda-feira 05/11/1888;

Lubricus Anguis, segunda-feira 05/11/1888;

Fetichismo, segunda-feira 01/04/1889;

Camoneana, segunda-feira 08/04/1889;

Odio e Amor, segunda-feira 06/05/1889;

A uma cantora, segunda-feira 08/07/1889;

Vana, segunda-feira 21/04/1890;

Amen: a Filinto de Almeida, segunda-feira 27/10/1890;

Anima Chloridis, domingo 17/05/1891.

\section{- Randolfo Fabrino:}

A Taça, segunda-feira 03/06/1889, segunda-feira 29/07/ 1889;

A ballada dos Amores, segunda-feira 30/09/1889. 
- Silva Alvarenga:

Orpheu, segunda-feira 05/08/1889;

O cajueiro, segunda-feira 12/08/1889.

- Silvestre de Lima:

O Passado, segunda-feira 08/09/1890.

- Sílvio Freire:

Alvorada, segunda-feira 03/03/1890;

Saudade (ao cidadão Bento Gomes), segunda-feira 05/05/ 1890;

Nova Phase, segunda-feira 11/08/1890;

Confissão, segunda-feira 15/09/1890.

- Soares de Sousa Junior:

Edelweiss, segunda-feira 07/10/1889.

- Teófilo Dias:

Saudade, segunda-feira 29/04/1889;

Latet anguis, segunda-feira 06/05/1889;

Soneto de uma moça pobre, segunda-feira 06/05/1889.

- Timotheo de Faria:

Umbra et lux, segunda-feira 18/08/1890.

- Urbano Duarte:

A lagrima, domingo 27/09/1891.

- Valentim Magalhães:

Renascimento (poema datado do Rio de Janeiro, 1888), segunda-feira 21/05/1888;

O violino (a J. Pereira da Costa, o exímio violinista), segunda-feira 17/12/1888;

A Vingança de Camões, segunda-feira 16/06/1890.

- Vera de Suckow:

Sonhando, segunda-feira 28/01/1889;

- Vicente de Carvalho:

Da carteira de um doudo (fragmento), segunda-feira 21/05/ 1888.

- Wenceslau de Queiroz:

A mandrágora, segunda-feira 20/09/1886;

A uma viajante, segunda-feira 02/05/1887;

Tesouro Oculto (a Leo de Afonseca), segunda-feira 18/07/ 1887;

Prece Mistyca (a meu filho), segunda-feira 01/08/1887;

A Clareira, segunda-feira 08/08/1887;

Porta sem gonzos, segunda-feira 08/08/1887;

Lenoa de Edel Weiss, segunda-feira 22/08/1887;

A Garça Exilada, segunda-feira 05/09/1887;

Dias Felizes, segunda-feira 17/10/1887;

(De Jean Richepin) Por seres tão formosa me atormentas, segunda-feira 07/07/1890;

A Clareira, segunda-feira 21/07/1890.

\section{Textos escritos em prosa}

- Adelina A. L. Vieira:

Visões, segunda-feira 12/12/1887.

- Afonso Guimarães:

Perfume das flores, domingo 18/01/1891.
- Artur Azevedo:

Noite de insomnia, segunda-feira 22/08/1887;

A toalha de Crivo: conto brazileiro, segunda-feira 17/02/ 1890;

Romantismo, segunda-feira 20/10/1890.

\section{- Castro Fonseca:}

Infância, Mocidade, Velhice (n'um Álbum), segunda-feira 13/10/1890.

\section{- Coelho Netto:}

Lagrima de Noiva, segunda-feira 23/09/1889;

Mercado de corações, segunda-feira 23/09/1889;

Lacrimatorio (das baladilhas), segunda-feira 19/07/1891.

- Cruz e Sousa:

Infância, Mocidade, Velhice (n'um Álbum), segunda-feira 13/10/1890.

- Filinto de Almeida:

O Beijo fatal, segunda-feira 30/06/1890.

- Ignotus:

Contos Brazileiros: Apprehensões d'uma mãe, domingo 04/01/1892.

- Ivan:

Scenas Brazileiras: A sucuryuba, domingo 02/08/1891.

- Joaquim Nabuco:

Ramalho Ortigão no Recife (crónica datada de novembro 1887), segunda-feira 09/01/1888.

- Júlia Lopes de Almeida:

A alma das flores, domingo 21/02/1892.

- Leopoldo de Freitas:

Flor Murcha, segunda-feira 27/10/1890.

- Lino d'Assumpção:

Mil e seiscentas léguas pelo Atlântico: a Bahia, segunda-feira 19/11/1888;

A Veneza brasileira (crónica de viagem sobre Pernambuco, extractada do livro Mil e seiscentas léguas pelo Atlantico), segunda-feira 26/11/1888.

- Luiz Guimarães:

Lá, domingo 30/08/1891.

- Luiz Gonzaga Duque-Estrada:

As laranjas (Fragmento de Memorias de um desgraçado), segunda-feira 11/10/1886.

- Marinho de Andrade:

No Horto, segunda-feira 23/9/1889.

- Medeiros e Albuquerque:

Um vencido, domingo 13/12/1891.

- Melo Morais Filho:

Nosso-Pai (tradicionalismo) (texto datado do Brasil), segunda-feira 27/08/1888.

\section{- Raul Pompeia:}

Durante a noite (conto do Natal), segunda-feira 10/10/1887.

- Valentim de Magalhães:

O sapatinho de Luiza, domingo 24/01/1892. 


\section{- Vicente de Carvalho:}

Da carteira de um doudo, segunda-feira 21/05/1888.

- Virgílio Várzea:

$O$ allemão doido, segunda-feira 25/11/1889;

Naufragio, segunda-feira 20/01/1890;

O mar, segunda-feira 27/01/1890;

Ultima lembrança, segunda-feira 22/09/1890;

Infancia, Mocidade, Velhice: N'um album (transcrito d' $O$ Mercantil, do Rio), segunda-feira 13/10/1890;

A Papagaio, segunda-feira 27/10/1890.

\section{Referências}

Jornal da Manhã: Diário Noticioso, Instructivo e Commercial. Porto, 1/9/1872-13/3/1892.

Jornal de Noticias: Diario. Porto, 4/6/1888-31/12/1891.

ALVES, Jorge Fernandes. Os Brasileiros: emigração e retorno no Porto Oitocentista. Porto: Gráficos Reunidos, 1994.

BESSA, Alberto. Jornaes da minha terra: subsídios para uma bibliographia do jornalismo portuense. O Tripeiro, Porto. S. 3, n. 40 (160), p. 242-244, 1927.

BRAGA, Teófilo. Parnaso Portuguez Moderno. Lisboa: Francisco Arthur da Silva, 1877.
BRANCO, Camilo Castelo ed. Cancioneiro alegre de poetas portuguezes e brazileiros. 4. ed. Porto: Livraria Chardron de Lello \& Irmão, 1927.

ORTIGÃO, Ramalho. As Farpas: o país e a sociedade portuguesa. Ed. Augusto de Castro. Lisboa: Clássica Editora, 1943.

PEREIRA, Elsa. Edições portuguesas das obras de Casimiro de Abreu. In: MARINHO, Cristina; TOPA, Francisco. Regresso ao exílio: Portugal e Casimiro de Abreu. Porto: CETUP, 2014. (no prelo)

RODRIGUES, Ernesto. Mágico Folhetim: Literatura e Jornalismo em Portugal. Lisboa: Editorial Notícias, 1998.

SILVA, Francisco Ribeiro da. Jornais e revistas do Porto no tempo de Camilo. Bibliotheca Portucalensis. S. 2, n. 5, p. 49-71, 1990.

SOUSA, Fernando. Jornal de Notícias: a memória de um século (1888-1988). Porto: Jornal de Notícias, 1988.

TENGARRINHA, José. História da imprensa periódica portuguesa. Lisboa: Portugália Editora, 1965.

TOUZOT, Jean. Portrait d'un animal très bizarre: l'écrivan journaliste. Littératures Contemporaines, n. 6. Paris, 1998. p. 9-22.

Recebido: 23 de janeiro de 2014 Aprovado: 15 de março de 2014 Contato: epereira@net.sapo.pt 